Please refer to the definitive version of this article when citing:

Peeters, P., Higham, J., Cohen, S., Eijgelaar, E. \& Gössling, S. (2018). Desirable tourism transport futures. Journal of Sustainable Tourism, DOI: 10.1080/09669582.2018.1477785.

\title{
Desirable tourism transport futures
}

Abstract

This editorial for the special issue on 'Desirable Tourism Transport Futures' explores approaches to transitioning the tourism sector to a sustainable emissions path. It starts by describing an undesirable tourism transport future associated with a business-as-usual scenario, which will inevitably cause the climate mitigation goals outlined in the Paris Climate Accord (2015) to soon become unattainable. We then outline a scenario for a climatically desirable future, the social and economic implications of which are explored. The challenge of mitigating climate change is critical to desirable tourism transportation futures, although to date relatively little attention has been paid to this aspect of sustainable tourism. This is an omission that must be urgently addressed. This special issue addresses desirable tourist transportation futures in relation to deep cut emissions reductions and, therefore, mitigation of climate change-induced environmental impacts. It is important that desirable tourism transport futures are critically considered in terms of both spatial and temporal scale. The scenarios that inform this introductory article provide some insights at the long-term macro-scale. These scenarios are associated with desirable and undesirable elements that will no doubt continue to be the subject of much debate and contestation. While these scenarios will represent both opportunities and threats to the full spectrum of tourism industry stakeholders, they should also inform manifold avenues of future research at a critical moment in the evolution of tourism transportation and the pursuit of the UN Sustainable Development Goals (2015-2030).

Keywords: Tourism transportation, futures, scenarios, policy, desirability, climate change

Tourism, transport and climate change

The workshop on 'Desirable Transport Futures', held in Freiburg im Breisgau in Germany in 2016, followed the first on 'Psychological and Behavioural Factors in Understanding and Governing Sustainable Mobility' (cf. Higham, Cohen, Peeters, \& Gössling, 2013) and the second on 'The Psychology of Governing Sustainable Tourism Mobility: Bridging the Science-Policy Gap' (cf. Cohen, Higham, Gössling, Peeters, \& Eijgelaar, 2016). This third iteration sought to address visions of desirable transport systems that have the potential to be actively taken up by wide cross-sections of society. Its main underlying aim was to explore inter-disciplinary approaches to transitioning the tourism and transport sectors to a sustainable emissions path. Before entertaining alternatives to the current unsustainable transport system, it is essential to know what desirable transport futures may look like. We envisaged a wide range of perspectives on what might be considered 'desirable' mobility, set in part against the Paris Conference of the Parties (COP21) on climate change in 2015. All papers in this special issue are outputs from this workshop and share a tourism transport point of departure. This focus distinguishes it from its sister special issue in Transportation Research Part D on Desirable Transport Futures (Gössling, Cohen, Higham, Peeters, \& Eijgelaar, 2018). In this overview paper, we take a macro perspective, based on desirable future scenarios, and explore the social and economic implications of the 
policy measures that must be taken if the tourism industry is to avoid derailing the Paris target to keep global temperature rise below $2^{\circ} \mathrm{C}$.

The existence of anthropogenic climate change is now beyond refute. There is strong scientific consensus about the role of human behaviour in climate change (IPCC, 2014c). Unmitigated climate change will cause, amongst other issues, significant negative impacts on global health (Watts et al., 2015); accelerating glacial retreat, accelerating glacial retreat, and exacerbate water scarcity (Schewe et al., 2014). It is expected that more general impacts on water availability will affect food production (Elliott et al., 2014); climate-forced migration (Mueller, Gray, \& Kosec, 2014), outbreaks of diseases (Medlock \& Leach, 2015) and associated cases of human conflict (Schubert et al., 2008).

Not only would one expect such futures generally to be considered undesirable, but worthy of intense political attention at all levels of global and sub-global governance. However, this is far from the current political reality. White (2016, p. 738) reveals how 'crimes of the powerful' are contributing to political inertia in climate policy:

It has been observed that the essential stumbling blocks to any type of progressive or concrete response to climate change include: downplaying that global warming is caused by human activity; blocking efforts to mitigate greenhouse gas emissions; excluding progressive, ecologically just adaptations to climate change from the political arena; and responding to the social conflicts that arise from climate change by transforming societies into fortress states that exclude the rest of the world. The net result is no action or inaction in addressing the key factors contributing to climate change, such as carbon emissions.

Though powerful players in tourism may feel compelled to act and effectively mitigate tourism's impact on climate change as "morally the right thing to do" (Coles, Zschiegner, \& Dinan, 2012, p. 15 ), so far the tourism sector has not been able to agree on a credible mitigation strategy (e.g. Scott, Hall, \& Gössling, 2016). This lack of effective mitigation action by the tourism sector is difficult to understand, as tourism is already heavily implicated in climate change in terms of both cause and effect, as demonstrated in "temporal and geographic shifts in tourism demand" and "environmental change and destination competitiveness within three major market segments (winter sports tourism, coastal tourism and nature-based tourism)" (Scott, Gössling, \& Hall, 2012, p. 213).

\section{Desirable futures and backcasting}

The term 'desirable futures' is not new. One early scientific reference to it comes from Strauss (1949), who in an article on politics and history tried to find "the best, or the just, political order" and searched history to do so. Strauss (1949, pp. 32-33) observes that a philosophically based answer to "the nature of political things has been superseded by the question of the characteristic 'trends' of the social life of the present and of their historical origins, and that the question of the best, or the just, political order has been superseded by the question of the probable or desirable future." He supports this transition because $17^{\text {th }}$ century philosophers like Locke mainly described what they deemed desirable, without grounding this opinion in history-based science. In current discourses about sustainable development, the same problem emerges where it is unclear to who's desire a development must be sustainable. Two decades later, Jantsch (1967) discusses forecasts of technological development and again finds that the desirability of futures 
has a strong personal bias and varies for instance across countries, nations, ethnicities, religions and 'race'.

The study of futures is often grounded in the development of 'scenarios'. The literature provides wide-ranging definitions of scenarios. Firstly, a scenario does not forecast the future, but rather provides a coherent and plausible, but not certain future state of the world (Bradfield, Wright, Burt, Cairns, \& van Der Heijden, 2005; Schwartz, 1996). Scenarios are commonly divided into groups, for instance, based on the dichotomies 'exploratory' versus 'normative' (Gordon, 1992; Prideaux, Laws, \& Faulkner, 2003; van Notten, Rotmans, van Asselt, \& Rothman, 2003). Exploratory scenarios start with a coherent set of assumptions and try to define plausible futures based on these assumptions. They are also referred to as 'what if' scenarios. Normative scenarios start with a 'desired future' and try to determine the policy measures to reach such a desired state. Often, the term 'backcasting' is used to describe this process (Prideaux et al., 2003, p. 476).

Backcasting is often used in environmental studies that explore the sustainable development of complex systems. Defining desirable futures forms the core of any backcasting scenario method and are often developed through consultation with stakeholders of the system studied (Oguz \& Ib, 1992; Quist \& Vergragt, 2006). Backcasting is a well-developed method in transport studies (Åkerman, 2005; Banister \& Hickman, 2012; Hickman \& Banister, 2005; Van Wee \& Geurs, 2004), but is also deployed in tourism research (Ceron \& Dubois, 2007; Page, Yeoman, Connell, \& Greenwood, 2010; Peeters \& Dubois, 2010). These studies share in common the fact that they define a desirable future regarding limitations posed by environmental issues. The Paris Agreement (UNFCCC, 2015), signed by all countries in the world (notwithstanding the recent decision by the US to withdraw from the accord), offers a collective commitment to limit $\mathrm{CO}_{2}$ emissions at a level that will keep global temperature rise below $2^{\circ} \mathrm{C}$. This commitment forms a commonly accepted base for $\mathrm{CO}_{2}$ emission reduction pathways in accordance with a desirable future.

\section{An undesirable tourism transport future}

To avoid the undesirable future of even a $2^{\circ} \mathrm{C}$ global temperature rise, the COP21 defined $\mathrm{CO}_{2}$ emission pathways (IIASA, 2015; Obersteiner et al., 2018). These scenarios show an extreme reduction of $\mathrm{CO}_{2}$ emissions by halving them up to every 25 years. How is the tourism sector fairing in a 'business-as-usual' (BAU) scenario? Or in other words, how large is the gap between this BAU scenario and the Paris defined emission pathways and global $\mathrm{CO}_{2}$ budget? The latter, which is the total $\mathrm{CO}_{2}$ humanity can emit this century and still stay with the Paris target, is calculated at rounded - $1000 \mathrm{GtCO}_{2}$ between 2015 and 2100 based on a range of estimates varying between 470 and $1270 \mathrm{GtCO}_{2}$ (Rogelj et al., 2016; van der Ploeg, 2018). The development of tourism's emissions is a function of the number of tourists, the distances these tourists travel and the transport modes they use (Peeters, 2017). While the number of trips is a relatively simple and linear but maximised function of income per capita and the total size of the global population, the transport distance and mode is a complex result of income, income distribution, prices, travel time, travel inconvenience and the 'lure of distance'. The attraction of distance may be seen as an odd factor, yet tourists link faraway or 'exotic' destinations to happiness (Ram, Nawijn, \& Peeters, 2013), while Pappas (2014) and Cohen and Gössling (2015) see distance as an important factor for social status and network capital. The majority of tourism $\mathrm{CO}_{2}$ emissions are caused by the distances travelled and transport modes used, the number and types of accommodation used, and the emission factors for these (Peeters, 2017). 
Based on combinations of ranges of assumptions for economic, demographic and technological development, Peeters (2017) calculated tourism's global $\mathrm{CO}_{2}$ emissions between 2015 and 2100 and found these to range between $18 \%$ and $53 \%$ of the global $\mathrm{CO}_{2}$ budget. For these calculations, a broad definition of tourism is used that includes every overnight visitor staying less than one year outside her/his usual environment (UNWTO, 2016, p. Annex 2), thus including holidays, visiting friends and relatives and business travel. Figure 1 shows the global BAU tourism $\mathrm{CO}_{2}$ emissions against the Paris global $\mathrm{CO}_{2}$ emission pathways and demonstrates that tourism in all cases disrupts these pathways between 2050 and 2080. This finding suggests that in the absence of active interventions to achieve deep cut emission reductions, the tourism sector is likely to render the Paris (2015) climate targets unachievable.

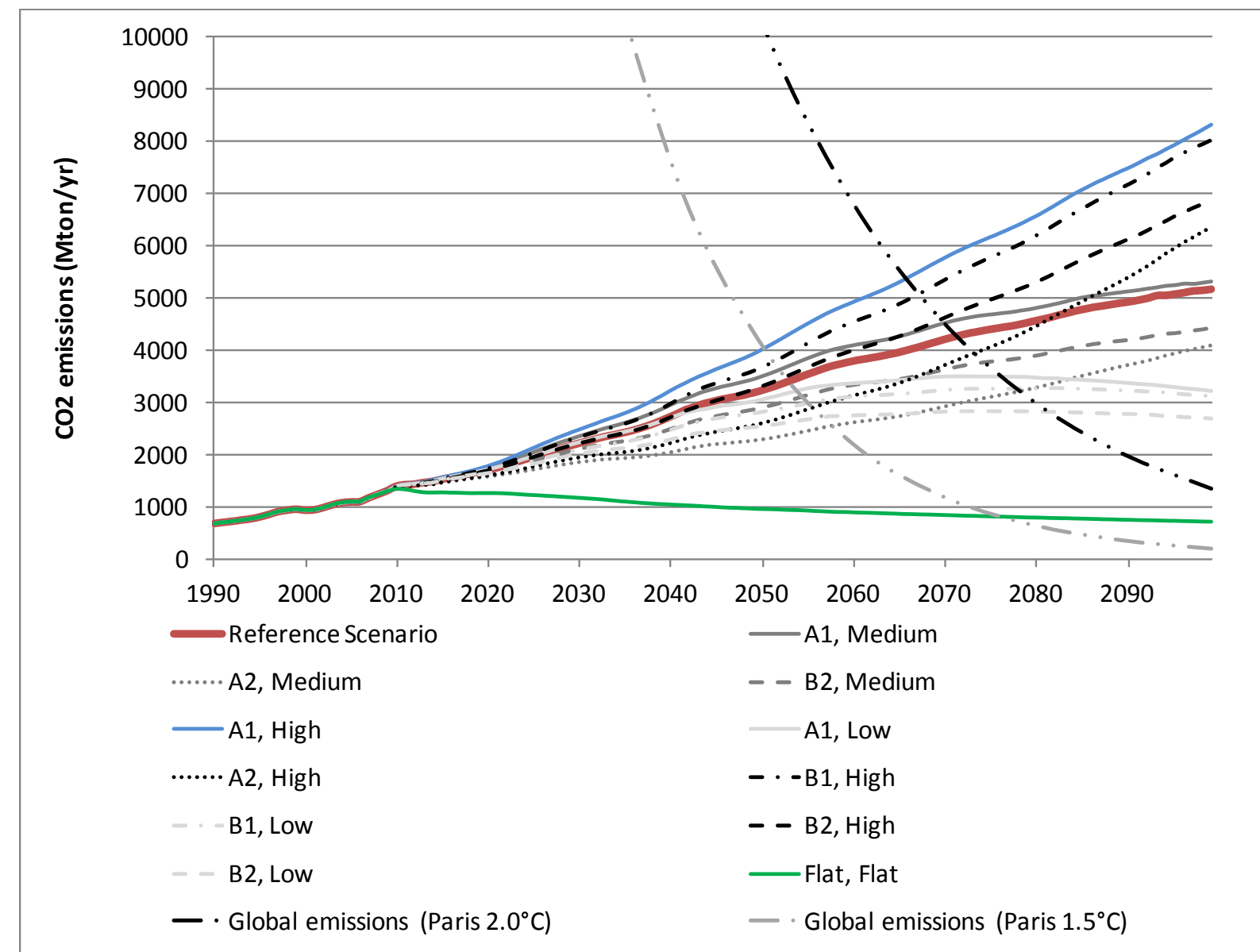

Figure 1: Overview of a range of tourism BAU scenarios as a function of economic and demographic growth assumptions. The Reference Scenario represents the B1, Medium scenario, where 'B1' designates the IPCC SRES economic scenario (IMAGE-team, 2006; IPCC, 2000) and 'Medium' a medium global population growth (United Nations, 2011). Source: Peeters (2017).

The Reference Scenario is a scenario with assumed medium economic and population growth, but not necessarily the most likely one. Let us assess the main changes under this scenario, comparing the situation in 2100 to the one in 2005. The number of trips increases by $340 \%$ (or 4.4 times more in 2100 compared to 2005), the number of guest-nights by $170 \%$, distance travelled by $880 \%$, total tourism revenues by $430 \%$, and $\mathrm{CO}_{2}$ emissions $370 \%$. The sector will use $28 \%$ of the total global $\mathrm{CO}_{2}$ budget between 2015 and 2100 . Air transport is responsible for $55 \%$ of tourism's $\mathrm{CO}_{2}$ emissions in 2015 , a share that rises to $76 \%$ in 2100 . The share of trips by air 
transport increases from $22 \%$ to $37 \%$. The car will remain the main transport mode of tourism transportation with a share of $48 \%$ in 2015 and $49 \%$ in 2100 . The most striking growth is the increase of travel distance by a factor of almost ten. Air transport volumes will increase by a factor of almost nine between 2015 and 2100, which is a major driver for the increasing $\mathrm{CO}_{2}$ emissions because the opportunities to reduce $\mathrm{CO}_{2}$ emissions per passenger kilometre are much less in aviation as in other transport modes or accommodation (Peeters \& Dubois, 2010). According to the data derived from the study by Peeters (2017), in the Reference Scenario $\mathrm{CO}_{2}$ emissions from the tourism industry are likely to make the Paris targets unachievable, while at the same time the contribution of the industry to the global economy stagnates.

A desirable tourism transport future

\section{Climatically desirable future}

The tourism sector expects long-term growth, and one can reason that this growth is a desirable future' for the sector. As shown above, this 'unlimited' growth also causes an 'undesirable future' regarding the impact on climate change. However, a range of measures can be taken to reduce emissions and avoid this outcome. So far, the only international tourism-related measures have been taken by the international aviation sector. These measures comprise a fuel efficiency standard (ICAO, 2016, 2017b) and an airline offsetting system (ICAO, 2017a), which together are assumed to lead to carbon-neutral growth from 2020 onwards. An evaluation of these ICAO measures by Peeters (2017) reveals that such a goal will most likely not be reached. The fuel standard has only a 1-2\% efficiency improvement potential. Secondly, compensation is taken from the open carbon credits market, which provides no guarantees for real and additional emissions reductions (Cames et al., 2016). Furthermore, as tourism's emissions by about 2070 will rise above the global emission goals set by the United Nations Framework Convention on Climate Change in Paris (UNFCCC, 2015), offsets will not be available in the longer term. The main effect is thus an initially small but gradually growing increase in the cost of flying, translating into steady reductions in demand for discretionary air travel over time. More needs to be done to explore and advance such interventions if tourism transport emissions are to meet global emissions reduction targets in the long-term.

These measures can be divided into six categories: alternative fuels/energy sources, improved energy efficiency and technology, investments in (alternative) infrastructure, taxes and subsidies, operational measures and behavioural measures. Such measures would include strong actions, including a carbon tax of USD1000/ton $\mathrm{CO}_{2}$, an aviation ticket tax of $200 \%$, biofuel subsidies up to $90 \%$, continued global investments in high speed rail of up to USD200 billion per year, and the most optimistic energy efficiency rates of change for all elements of tourism introduced at a reasonable path. A combination of all these policy strategies within the dynamic Global Tourism \& Transport Model (GTTMdyn) (Peeters, 2013) still fails to reduce emissions significantly compared to 2015 emissions. A climatically sustainable level (about 82\% reduced emissions compared to 2005 and taking about $3.5 \%$ of the global carbon budget) requires one additional measure: a regulated maximum capacity for air transport (for instance a maximum global fleet or airport slot capacity). This ultimate scenario causes significant losses in number of trips, revenues and total distances that can be travelled for tourism. That is unfortunate, as the tourism sector serves both economic - jobs, GDP - and social purposes - the freedom to travel (Font \& Hindley, 2016) for recreation, leisure, business and visiting friends and relatives. A proxy for this economic purpose could be the total revenues from tourism. A proxy for these social aspects may be found 
mainly in the number of trips and to a lesser extent in the distances people travel. If those reduce significantly, a proportional reduction of freedom may result.

By analysing these results and further experimenting with the GTTMdyn, it appears that a clever combination of the measures could mitigate most of the economic and social losses, while providing only slightly less emission reduction $(72 \%$ and $5 \%$ of the total carbon budget between 2015 and 2100). This 'Economic Mitigation Scenario' is characterised as follows:

- Revenues in 2100 are 3\% higher than in the Reference Scenario (RS) and 443\% higher than in 2005.

- The number of trips increases by $313 \%$, which is only $5 \%$ lower than in the RS.

- The number of nights will increase by $273 \%$, which means total guest-nights will be almost 40\% larger than in the RS; it is here where the sector keeps its revenues high.

- The total distance travelled will increase by 355\% between 2005 and 2100, but will be about half of the total in the RS.

- Total in-travel time will reduce by $16 \%$ compared to the RS.

- The share of trips by car will rise from $20 \%$ in 2015 to $70 \%$ in 2100 .

- The share of trips by other transport (rail, coach) will still reduce from $30 \%$ in 2015 to $25 \%$ in 2100 .

- The share of trips by air transport will reduce from 22\% to 5\% between 2015 and 2100.

- The distribution of trips over distance classes will stay more or less the same as in 2015, while in the RS, the long-haul distance will take significantly larger shares.

- The average travel speed will decline from $239 \mathrm{~km} / \mathrm{hr}$ in 2015 to $189 \mathrm{~km} / \mathrm{hr}$ in 2100 , compared to the RS average of $344 \mathrm{~km} / \mathrm{hr}$ in 2100 . This reduction is mainly caused by the shift in shares of transport modes away from the fastest.

- For medium-haul distance trips, high-speed rail will take a much larger share. In terms of transport (passenger-km; pkm), the share of air transport declines from 58\% in 2015 to $14 \%$ in 2100 (76\% in the RS), car increases from $26 \%$ to $47 \%$ (16\% in RS) and other transport (rail, coach) increases from $16 \%$ to $39 \%$ ( $9 \%$ in RS).

In the following two sections we will discuss the social and economic desirability of this climatically desirable future for tourism.

\section{Social desirability}

The Economic Mitigation Scenario for tourism above will have heterogeneous effects both across and within societies. These effects will be determined by the nuances of the policy measures that will be needed to achieve this scenario, and consideration must be given to how different policies add to, or potentially detract from, conceptions of social justice. Discussions of justice concerns associated with transport are gaining salience: they emphasise that care must be taken through governance not to perpetuate or amplify injustice through policy decisions that allocate more resources to the most privileged in societies (Mullen \& Marsden, 2016).

A basic starting point in discussing the social desirability, and thus fairness or justness, of this scenario is therefore to consider the differential impacts on richer versus poorer populations at a global level. While in theory, the Economic Mitigation Scenario would allow for currently poorer nations to enjoy increases in transport speed and distance, more developed nations would on the whole have to take fewer trips by air transport, develop high-speed rail where appropriate and reduce overall distances travelled. At more individual levels, the global elite, who are to be found within most nations, and who have become accustomed to travelling fast, far and frequently 
(Cohen, Hanna, \& Gössling, 2017), will have to adjust to slower modes of tourism transport (i.e. car, coach and rail) and longer stays, especially when travelling at short- and medium-haul scales. This will be especially challenging within the context of business travel, as most of this, at a global level, is facilitated by flying (Beaverstock, Derudder, Faulconbridge, \& Witlox, 2009). Reining in both business and leisure frequent flyers will be crucial, and to do so justly through taxation is likely to require inventive policy measures, such as the introduction of heavy frequent flyer levies (Murray \& Young, 2017).

Slower travel with longer stays may benefit those privileged enough to take their time; time is a valuable commodity and many within societies will be constrained by work and other obligations that will prevent the use of car, coach or rail as modal choices at medium-haul scales. Where these trips are experienced as discretionary, they may be sacrificed. But where they involve travel that is perceived as obligatory, such as that associated with maintaining family obligations, and providing support and care, through visits (Janta, Cohen, \& Williams, 2015), the impacts will be felt as deeply undesirable. This may be especially the case for migrant workers, seasonal migrants and for diasporic communities, whose short-term or circular journeys will be constrained as a result.

Set against the potential socially undesirable aspects of the scenario, it is important that policy makers consider the social desirability of transport futures, which can be considered at various scales of analysis. The global injustices of the current aeromobility regime have been widely documented. Young, Markham, Reis, and Higham (2015) consider tourist air travel in relation to Beck's (1992) risk society as a form of contemporary consumption that is now known to produce global environmental risks far beyond the individual interests of those who engage in pleasure travel. Young et al. (2015) offer an expression of the BAU model in which the choice to fly remains intact, although ever more defined along the lines of class and geography. They state that the "geography of this nigh capitalist social order will be characterised by segregation, where the super-rich wall themselves off from an otherwise stricken planet, in highly-secured, affluent and comfortable 'evil paradises'” (Young et al., 2015, p. 8). Avoiding such a scenario, for which Dennis and Urry (2009) coin the term 'regional warlordism', highlights beyond any doubt the social desirability of a globally just and equitable tourist transport future.

Indeed Urry (2003) also alludes to an important aspect of global social desirability in the extended (inter-generational) temporal scale, calling for consideration to be given to issues of equity in relation to future generations "...to ensure that the conditions for [air travel] are not all used up on the hypermobile present" (Urry, 2003, p. 172). It is critical that desirable transport futures accommodate global social and environmental justice. Following the Paris Climate Accord (2015) and under CORSIA ${ }^{1}$ the efforts of ICAO $(2016,2017$ a) to respond to aviation emissions allow for all flights to or from Least Developed Countries (LDCs), Small Island Developing States (SIDs) and Landlocked Developing Countries (LLDCs) to be exempt from the carbon offsetting and reduction scheme for international aviation. This has been recognised by some as a potential loophole that would allow airlines to re-route long haul flights through developing countries to exempt themselves from the costs of carbon offsetting under CORSIA. It is perhaps ironic that while such a measure might bring new air travel possibilities to those who are currently largely or entirely denied the opportunity of air travel, the barrier of cost and the globally dispersed environmental impacts of aviation are likely to remain unchanged.

${ }^{1}$ On Friday 7th October 2016 the ICAO $39^{\text {th }}$ General Assembly passed a resolution to implement a global market-based mechanism (GMBM), the 'Montréal Agreement', in the form of a carbon offsetting and reduction scheme for international aviation (CORSIA). 
At the opposite end of the spatial scale, it is equally important to consider the social desirability of tourist transport futures at the level of the individual. Significant change in the mode share of air transport measured in trips is likely to bring significant health benefits to those typically less privileged residents in communities that are located in close proximity to, and in the shadow of the flight paths of major airports (Mahashabde et al., 2011; Steve et al., 2015). Reduced speed and distance may reduce the increasing incidence of death caused by tourist vehicle accidents, such as those caused by drivers who rent vehicles upon disembarking from long-haul flights. Health and equity benefits are likely to accrue to the residents of gateway destinations that move towards low carbon urban mobility transitions (Macmillan \& Mackie, 2016). The move towards active urban transportation systems through initiatives such as dedicated cycleways, bicycle sharing schemes and increasing pedestrianisation are associated with significant individual health gains in terms of reductions in risk of personal injury caused by vehicle accidents involving cyclists and pedestrians, and reduced air pollution causing respiratory morbidity or mortality (Hopkins \& Higham, 2016).

The social desirability of a less aeromobile society brings the very existence of hypermobile societies into question. Drawing upon Planck's maxim 'speed $=$ distance $\div$ time', Goulden (2011) reflects upon the pursuit of speed and the simultaneous destruction of its co-variables, distance and time, in contemporary societies. In doing so, he points out some of the ironies of the prospects of the vacuum Mag-Lev train which, like Elon Musk's hyperloop2, will afford travel through tunnels at speeds greater than jet air travel. Goulden (2011) asks 'is this really desirable?' While such technologies will redefine the parameters of speed, distance and time still further, Goulden argues that the relentless pursuit of speed diminishes and will ultimately destroy the journey itself. He states that "The logic of speed ensures that the journey - that is the experience of time through space - is itself ever diminished, as distance slips by $36,000 \mathrm{ft}$ below, or is smeared across the train window at $200 \mathrm{mph}$. The proposed Mag-Lev vacuum is surely the logical end-point of this process: hurtling through a black, airless void at multiples of the speed of sound" Goulden (2011, p. 3).

Clearly the scope for socially desirable health benefits may extend to those who are hypermobile. Cohen and Gössling (2015) propose the possibility that less frequent travel among the hypermobile members of a society may translate into stronger family connections, local social ties and (community) social capital. Reductions in speed and distance may allow the 'exotic' qualities of distant destinations to be restored, while also restoring unique aspects of the journey that have been compromised by the relentless pursuit of speed (Dickinson \& Lumsdon, 2010). These are interesting and important points to contemplate in relation to the social desirability of tourist transportation futures and aspects of the tourist experience, from the perspective of tourists themselves.

\section{Economic desirability}

Any discussion on economic desirability in the context of transportation will have to take a starting point in the development of the global economic system: global economic growth is to some degree predicated by transportation systems (Gilbert \& Perl, 2008), but wealth is also the main driver of growth of transport demand (Schäfer \& Victor, 2000). Industry has for decades maintained that without growth in air travel, the global economic system will suffer with concomitant detrimental consequences for employment and economic growth (Doganis, 2006).

${ }^{2} \mathrm{~A}$ vacuum sealed tube through which a pod can travel without air resistance or friction transporting people at high speeds with little energy expenditure. 
Yet, with an emerging debate on 'overtourism' (Kamp, 2017), there is a need to shine some light on the rhetorical foundations of such claims. How far can economic systems, and tourism within it, continue to grow in a world characterized by planetary boundaries (Rockstrom et al., 2009)? Just in terms of the number of humans claiming a share of Earth's resources, this will be difficult: The world population is poised to reach 7.5 billion in 2018; China alone is now home to close to 1.4 billion people (CIA, 2018). By 2100, there will be up to 12.3 billion people, and that number is expected to continue to grow after the turn of the century (Gerland et al., 2014). Not only will the world economic system have to accommodate a rapidly growing workforce, with newly emerging debates about the growing 'surplus population' (Tyner, 2013); this population will also have to be provided with sustenance (Conijn, Bindraban, Schröder, \& Jongschaap, 2018), with implications for the aspiration to eradicate extreme poverty as outlined in the Sustainable Development Goals (SDGs; United Nations, 2018).

Against this development challenge, 'economic desirability' must address climate change (IPCC, $2014 \mathrm{~b}$ ) and the distribution of economic resources. Recent publications on economic equity and distribution have highlighted the fact that wealth is unevenly distributed, and increasingly so (Piketty, 2015). In its report, 'An economy for the 99\%', Oxfam claims that the richest eight individuals in the world own the same wealth as the 3.6 billion of the poorest, representing half of the world's population (Hardoon, 2017). During the 2015 US pre-elections, presidential candidate Bernie Sanders highlighted that $99 \%$ of new income is going to the top $1 \%$ of the population (Sanders \& Sharockman, 2015). While the credibility of these claims is unconfirmed, there can be little doubt that we live in an economically contracting world, in the sense that a growing share of global wealth is owned and commandeered by an economic elite. Forbes (2018) lists 2,043 billionaires, worth US\$7.7 trillion. To move a person out of extreme poverty, one of the SDGs, means to increase daily per capita incomes above US\$1.90 in purchasing power parity (PPP; Hubacek, Baiocchi, Feng, \& Patwardhan, 2017). Yet, of relevance with regard to climate mitigation objectives is the fact that while poverty eradication on the US $\$ 1.90$ level could be achieved without jeopardizing decarbonisation goals, lifting humanity above an income of $\$ 2.97$ PPP will challenge reduction targets (Hubacek et al., 2017).

Climate change and economic distribution have relevance for tourism from at least two different viewpoints. First of all, tourism is an important part of the global economy, with low-level barriers to entry and low salaries. It is a system of vast employment-generating importance (Mowforth \& Munt, 2015; Sharpley \& Telfer, 2014), but it is also a system that incurs a high carbon cost, as outlined above. While the UNWTO and WTM (2017) highlight the sector's importance in job generation, positioning 'growth' as an endeavour in its own right that pre-empts critical debate, there is, as earlier outlined in this paper, very limited evidence of a system that is aligned with its environmental impacts. Yet, whatever is economically desirable must be ecologically sustainable (Costanza et al., 1997) and with a growing population participating in ever more carbon-intense forms of tourism, the prospect of a sustainable tourism sector is increasingly bleak (Buckley, 2012).

A parallel debate will have to arise regarding the concentration of travel, defined against travel frequencies. There is much evidence of hypermobile travel classes (Cohen et al., 2017; Gössling, Ceron, Dubois, \& Hall, 2009), and the importance of heavily skewed distributions of emissions is increasingly acknowledged and understood. On a global scale, emissions from transportation ranged between less than $0.1 \mathrm{t} \mathrm{CO}_{2}$ per capita in India to $4.5 \mathrm{t} \mathrm{CO}_{2}$ in the United States (data for 2005; Schäfer, Heywood, Jacoby, \& Waitz, 2009). While this highlights great disparities in mobility patterns between countries, frequencies of individual travel within countries are of equal 
importance. Specifically with regard to travel, Brand and Boardman (2008) found that the 10\% of the most frequent travellers in the UK accounted for $43 \%$ of personal travel emissions. In a more recent, global assessment, Hubacek et al. (2017, p. 1) concluded:

"We find that in 2010, the global elite or top $10 \%$ of income earners were responsible for $36 \%$ of global carbon emissions whereas the extreme poor accounting for 836 million people, that was $12 \%$ of the global population, contributed only $4 \%$ of global emissions."

It follows that if a desirable economy is one where the SDGs are realized, including stabilization of the climate system as well as the eradication of extreme poverty, the lifestyles of the $0.1 \%$, the $1 \%$, and the $10 \%$ will have to be addressed. These clusters refer to the class of the superrich (the $0.1 \%$ ), with multiple households, private aircraft, helicopters and super-yachts (Beaverstock \& Faulconbridge, 2014); the global elite of high-income takers (the 1\%), who participate in multiple holidays per year, as well as high business trip numbers (Brand \& Boardman, 2008; Gössling et al., 2009; Lassen, Laugen, \& Næss, 2006); and, finally, the wider upper middle class (the 10\%), who contribute significantly to emissions through their transport patterns (e.g. Gössling, Lohmann, Grimm, \& Scott, 2017).

The papers in this special issue

The challenge of mitigating climate change explicitly motivated two of the papers in this special issue (Hanna \& Adams, 2017; Kantenbacher, Hanna, Miller, Scarles, \& Yang, 2017). The other three find implicit motivation in mitigating greenhouse gas emissions and reducing environmental impacts (Hall \& Ram, 2017; Scuttari, Orsi, \& Bassani, 2018; Smith, Robbins, \& Dickinson, 2017). Hanna and Adams (2017) analyse talk about holidays to reveal discursive strategies tourists use to maintain positive self-representations, despite the conflict between their flying decisions and personal desires to consume sustainably. These denial strategies constitute socially organised barriers to sustainable travel behaviour. However, Hanna and Adams (2017) also found several respondents that resisted this social denial and chose to not fly, showing that there is scope for behaviour change, but only if achieved within the social context of everyone changing. Kantenbacher et al. (2017, p. 1) assessed the willingness of tourists to sacrifice flying over other behavioural sacrifices and found that "voluntary reductions in flying are more plausible than other modes of pro- environmental sacrifice". The study shows that when people are forced to choose, they realise that flying is of less importance when compared to daily activities such as using a car or a mobile phone. The effectiveness of sacrifice of other behaviours in terms of emission reductions was not included. Since flying is a very strong determinant for the size of one's ecological footprint, this finding is cause for some optimism in the willingness of people to change flying habits.

Scuttari et al. (2018) study the effects of traffic management to reduce the use of the private car by tourists at two mountain passes in the Dolomites (Italy). Their conclusion is that this will require both 'carrot' and 'stick' policy measures, but that these will only be effective if designed with local considerations in mind. Importantly, they find that such measures, even when relatively strong, are well accepted by the tourists and inhabitants of the destinations. Taking the New Forest in southwest England as their research focus, Smith et al. (2017) study tourism transport to and in a nature reserve. Their research is loosely motivated by mitigating climate change, among other externalities. They take a social practices approach and show some evidence that sustainable transport improvements will work if founded in understanding visitor practices. Rightly, they observe that even tourists travelling by car to the New Forest, which generally 
would not seen as a sustainable form of transport, would still be far more desirable from the point of greenhouse gas emissions than any British tourist flying abroad. Finally, Hall and Ram (2017) review the walkability of cities. They do not find a clear relationship between walkability and number of visitors, and attribute this to flaws in the methods available to measure walkability for tourists.

\section{Dreams, nightmares or desirable tourism transport futures?}

In this introductory paper we address tourism transportation at the macro-scale to inform a debate about a global climatically sustainable tourism future. Runaway climate change scenarios are considered by most to present undesirable nightmares. Of course, there are different pathways to avoid this nightmare, each associated with different interpretations of desirability. In this paper we highlight one macro-solution - the Economic Mitigation Scenario - and give some consideration to possible manifestations of this scenario at the micro-scale. While a desirable tourism future at the macro-scale is conceivable, and from almost all points of view economically, social, environmentally - desirable, it is important to ask how such futures may play out at the micro-scale. The impacts of macro-scale changes on the lives of individuals will largely determine the desirability of such futures.

The Economic Mitigation Scenario tells us that between now and 2100 there will be growth in tourism which equals the BAU-scenario in terms of jobs, revenues, trips and guest-nights. It is likely that there will be growth in travel distances, but the total distance will not be nine to ten times current volume (passenger-kms), but three to four. The gains will be in short and mediumhaul travel and the losses in a stagnation of demand for long-haul travel. Long-haul air travel may be confronted with successive price increases over time which, socially, is likely to be considered undesirable for people with globalised social networks and transnational family ties. If such pricing mechanisms unfold gradually over time the immediate effects for the current generation of regular fliers, so accustomed to high levels of relatively cheap and convenient long-haul mobility, may be softened. The challenge will be to rethink and recast expectations of current high (aero)mobility, while persuading coming generations to adopt the more sustainable tourism travel behaviours that are urgently required to stabilise emissions in line with the Accord forged in Paris (2015).

Economically, desirability is defined by two aspects: the economic opportunities the sector provides in terms of jobs, and local development, and the distribution of travel across populations. The current distribution of travel is very uneven, with members of a very small hypermobile elite yet to be made accountable for their disproportionate carbon footprints, while a very significant proportion of the global population - which shares in the negative externalities of the global transportation regime - is largely or entirely excluded from travel. The Economic Mitigation Scenario would specifically help those starting to travel at short to medium-haul trips by providing far better developed alternatives, such as (high-speed) rail and electric transport, than currently exist. At the same time it will be necessary to rein in the hypermobile elite and redistribute travel among members of the global population. Constraining long-haul air travel under the current transportation regime may cause economic and development issues for remote small developing island states (Pang, McKercher, \& Prideaux, 2012), but unchecked climate change under BAU presents an existential threat to many micro island states (IPCC, 2014a). The existential issue is difficult to compensate economically, but reduced travel could be compensated by a development fund based on a global or sub-global emissions taxation mechanism. 
The Economic Mitigation Scenario represents the scientific treatment of a set of circumstances that aim to combine $\mathrm{BAU}$ economic growth in the tourism sector with $\mathrm{CO}_{2}$ emission reductions as agreed by the global community in Paris in 2015. While it represents an environmentally and climatically 'desirable future', it will inevitably raise several very valid and important questions in the mind of the reader. What will be the detailed economic consequences for the tourism sector, and the wider economy? Is the tourism industry treated equally by national and international climate policies when considered against other sectors? Is it possible to assume that large investments will improve the environmental performance of tourist transportation in a changing economy? What are the prospects that the 'scientifically-desired' scenario will become a 'politically desirable scenario'?

A fundamental assumption underpinning the Economic Mitigation Scenario is that the tourism sector should more or less achieve the same emission reduction pathway as agreed in Paris for all sectors. In terms of total emissions this would represent equal treatment among sectors of the economy. However, one of the key drivers of growth in tourism emissions - air transport - poses a 'wicked problem'. It is one of the 'difficult sectors' to mitigate (Energy Transitions Commission, 2017), because technological improvements for aircraft fail to exceed future projected volume growth (Alonso et al., 2018). So where many other sectors may have technological options to reduce emissions, such options are not available to aviation. In the absence of technical solutions severe volume restrictions seem inevitable. The post-Paris 2015 implications for the aviation sector, whatever form it may take, will have wide-ranging social, economic and environmental ramifications. It is critically important that the future interplay of global tourism system elements which, in the case of aviation, have extensive social, economic and environmental impacts are modelled and understood (Reynolds et al., 2007). A carbon constrained aviation future would cause loss of employment in some sectors, and compromised accessibility in some (more remote) destinations. Equally, currently $78 \%$ of total tourism does not depend on aviation, and significant benefits in terms of employment and accessibility for destinations that are accessible by low or zero-carbon modes of transportation may be anticipated. The sector-proposed CORSIA offsetting scheme is set to redistribute finance to other sectors to reduce emissions, which may cause job losses within the tourism sector. Equally, destinations that are recognised as leaders in sustainable transportation may ensure that economic redistribution, as opposed to loss, occurs within the tourism sector.

It is also important to consider the potential implications of a cap on aviation growth, as proposed in the Economic Mitigation Scenario, for the wider economy (Dwyer, Forsyth, Spurr, \& Hoque, 2012). Reduced aviation will affect air freight of fresh food to developing countries. While food imports represent a small share of air cargo (less than $1 \%{ }^{3}$ ), the geographical distribution of future air transportation services will be regulated directly or indirectly, as indicated in the details of CORSIA which makes specific mention of LDCs, SIDs and LLDCs. It is important to note that the Economic Mitigation Scenario is one that forecasts reduced annual average growth between 2015 and 2100 from $2.5 \%$ to $1.7 \%$ /year, which still represents growth far beyond population growth (about 0.5\% per year), and thus not reducing food transport in the future. Furthermore, in the Economic Mitigation Scenario air transport is substantially replaced by rail transport. The development of high speed rail in China shows the capacity of countries in

\footnotetext{
${ }^{3}$ See for instance fresh food figures for US food imports in https://kanhaul.com/news/kan-hauls-foodtransportation-infographic/.
} 
transition to develop more sustainable systems of transport provision. Developing countries like Morocco are now developing extensive high-speed rail systems ${ }^{4}$.

It is clear that technology advances will play a critical role in moving rapidly towards a zerocarbon tourism transportation future (Hopkins \& Higham, 2016). Herein lie further questions regarding the capacity of a carbon constrained economy to invest in new transportation technology and other mitigating measures. Yet under the Economic Mitigation Scenario revenues are the same as BAU in which case overall the economic capacity to invest is not diminished, but shifted away from aviation to more low-carbon rail and private vehicle transport solutions. Furthermore, while the revenues for aviation will grow at a much slower pace than in BAU, they will still increase while volume (passenger-kms) declines. This means revenues per pkm will increase, giving some economic room for continued and increasing science and development, and technology investment. At the same time, efficiency improvements in aviation become less important with reduced volumes; in other words, less investments are needed.

There is no doubt that mitigating climate change while seeking to perpetuate the social and economic benefits of tourism is a 'formidable policy challenge' (Reynolds et al., 2007). Will it be possible, in a democracy, to make the radical changes in policies required to transition to the Economic Mitigation Scenario? It may seem that few, if any, economically developed democratic countries are taking sufficient steps towards the measures agreed in Paris in 2015. However, all signatories of the Paris Climate Accord, including the US, are required to establish and meet national mitigation goals and plans that comply with the agreed upon National Determined Contributions (NDCs). Climate and Energy College (2018) provides a list of all country's NDCs showing that all advanced economies are taking strong measures with the aim of very substantial emission reduction. For instance, the Netherlands has adopted the target of reducing emissions by $49 \%$ in 2030 from the 1990 baseline. One consequence of this is the 2018 government decision to stop gas production in the northern provinces of the Netherlands completely by 2025 . Similarly, on the $12^{\text {th }}$ April 2018 the New Zealand government announced a ban on offshore oil exploration as part of its plans to transition to a zero-carbon economy by 2050, noting that "[u]nless we make decisions today that will essentially take effect in 30 or more years' time, we run the risk of acting too late and causing abrupt shocks to communities and our country" (Davison, 2018, p. 1). Quite apart from perceptions of the current reality of mitigation policies, but closely linked to it, one may question the role of science in policymaking. The role of science is critical to inform the formidable tourism transport policy challenges that confront us, and to respond to the undesirable truths of climate change.

\section{References}

Åkerman, J. (2005). Sustainable air transport - on track in 2050. Transportation Research - D, 10(2), 111126.

Alonso, J., Catalano, F., Cumpsty, N., Eyers, C. J., Goutines, M., Grönstedt, T., Hileman, J., Joselzon, A., Khaletskii, I., Mavris, D., Ogilvie, F., Ralph, D., Sabnis, J., Wahls, R., \& Zingg, D. (2018). Independent expert integrated technology goals assessment and review for engines and aircraft. 2017 independent expert integrated review panel. DRAFT version for review. Montreal: ICAO.

Banister, D., \& Hickman, R. (2012). Transport futures: Thinking the unthinkable. Transport Policy, In press. Beaverstock, J. V., Derudder, B., Faulconbridge, J. R., \& Witlox, F. (2009). International business travel: some explorations. Geografiska Annaler: Series B, Human Geography, 91(3), 193-202.

Beaverstock, J. V., \& Faulconbridge, J. R. (2014). Wealth segmentation and the mobilities of the super-rich. In Elite mobilities (pp. 40-61). London: Routledge.

\footnotetext{
${ }^{4}$ See https://www.moroccoworldnews.com/2018/02/239911/morocco-high-speed-train/.
} 
Beck, U. (1992). Risk society: Towards a new modernity (Vol. 17). London: Sage.

Bradfield, R., Wright, G., Burt, G., Cairns, G., \& van Der Heijden, K. (2005). The origins and evolution of scenario techniques in long range business planning. Futures, 37, 795-812.

Brand, C., \& Boardman, B. (2008). Taming of the few-The unequal distribution of greenhouse gas emissions from personal travel in the UK. Energy Policy, 36(1), 224-238.

Buckley, R. (2012). Sustainable tourism: Research and reality. Annals of Tourism Research, 39(2), 528-546.

Cames, M., Harthan, R. O., Füssler, J. r., Lazarus, M., Lee, C. M., Erickson, P., \& Spalding-Fecher, R. (2016). How additional is the Clean Development Mechanism? Analysis of the application of current tools and proposed alternatives (No. CLIMA.B.3/SERI2013/0026r). Berlin: Öko-Institut.

Ceron, J. P., \& Dubois, G. (2007). Limits to Tourism? A Backcasting Scenario for Sustainable Tourism Mobility in 2050. Tourism and Hospitality Planning \& Development, 4(3), 191 - 209.

CIA. (2018). The World Factbook 2018. Retrieved 1 February 2018, 2018, from https://www.cia.gov/library/publications/the-world-factbook/geos/xx.html

Climate and Energy College. (2018). NDC \& INDC Factsheets. Retrieved 27-04-2018, 2018

Cohen, S. A., \& Gössling, S. (2015). A darker side of hypermobility. Environment and Planning A, 47(8), 1661679.

Cohen, S. A., Hanna, P., \& Gössling, S. (2017). The dark side of business travel: A media comments analysis. Transportation Research Part D: Transport and Environment.

Cohen, S. A., Higham, J., Gössling, S., Peeters, P. M., \& Eijgelaar, E. (2016). Finding effective pathways to sustainable mobility: Bridging the science-policy gap. Journal of Sustainable Tourism, 24(3), 317334.

Coles, T., Zschiegner, A.-K., \& Dinan, C. (2012). Climate change mitigation policy and the tourism sector: perspectives from the South West of England. Journal of Policy Research in Tourism, Leisure and Events, 5(1), 1-27.

Conijn, J. G., Bindraban, P. S., Schröder, J. J., \& Jongschaap, R. E. E. (2018). Can our global food system meet food demand within planetary boundaries? Agriculture, Ecosystems \& Environment, 251, 244-256.

Costanza, R., d'Arge, R., Groot, R. d., Farberk, S., Grasso, M., Hannon, B., Limburg, K., Naeem, S., O'Neill, R. V., Paruelo, J., Raskin, R. G., Suttonkk, P., \& van den Belt, M. (1997). The value of the world's ecosystem services and natural capital. Nature, 387, 253-260.

Davison, I. (2018). Prime Minister Jacinda Ardern bans oil exploration. Retrieved 02-05-2018, from https://www.nzherald.co.nz/nz/news/article.cfm?c_id=1\&objectid=12030956

Dennis, K., \& Urry, J. (2009). After the car. Cambridge: Polity.

Dickinson, J., \& Lumsdon, L. (2010). Slow Travel and Tourism. London: Earthscan.

Doganis, R. (2006). The airline business. Oxon, UK: Routledge.

Dwyer, L., Forsyth, P., Spurr, R., \& Hoque, S. (2012). Economic Impacts of a Carbon Tax on the Australian Tourism Industry. Journal of Travel Research, 52(2), 143-155.

Elliott, J., Deryng, D., Müller, C., Frieler, K., Konzmann, M., Gerten, D., Glotter, M., Flörke, M., Wada, Y., Best, N., Eisner, S., Fekete, B. M., Folberth, C., Foster, I., Gosling, S. N., Haddeland, I., Khabarov, N., Ludwig, F., Masaki, Y., Olin, S., Rosenzweig, C., Ruane, A. C., Satoh, Y., Schmid, E., Stacke, T., Tang, Q., \& Wisser, D. (2014). Constraints and potentials of future irrigation water availability on agricultural production under climate change. Proceedings of the National Academy of Sciences, 111(9), 32393244.

Energy Transitions Commission. (2017). Better Energy, Greater Prosperity. Achievable pathways to lowcarbon energy systems. London: The Energy Transitions Commission.

Font, X., \& Hindley, A. (2016). Understanding tourists' reactance to the threat of a loss of freedom to travel due to climate change: a new alternative approach to encouraging nuanced behavioural change. Journal of Sustainable Tourism, 25(1), 26-42.

Forbes. (2018). Forbes 2017 Billionaires list: Meet the richest people on the planet. Retrieved 1 February 2018, 2018, from https://www.forbes.com/billionaires/ - f9087a0251c7

Gerland, P., Raftery, A. E., Ševč́́ková, H., Li, N., Gu, D., Spoorenberg, T., Alkema, L., Fosdick, B. K., Chunn, J., \& Lalic, N. (2014). World population stabilization unlikely this century. Science, 346(6206), 234-237.

Gilbert, R., \& Perl, A. (2008). Transport revolutions. Moving people and freight without oil. London: Earthscan.

Gordon, T. J. (1992). The Methods of Futures Research. Annals of the American Academy of Political and Social Science, 522, 25-35.

Gössling, S., Ceron, J. P., Dubois, G., \& Hall, C. M. (2009). Hypermobile travellers. In S. Gössling \& P. Upham (Eds.), Climate change and aviation: Issues, challenges and solutions (pp. 131-150). London: Earthscan. 
Gössling, S., Cohen, S., Higham, J., Peeters, P. M., \& Eijgelaar, E. (2018). Desirable transport futures. Transportation Research Part D: Transport and Environment, in press.

Gössling, S., Lohmann, M., Grimm, B., \& Scott, D. (2017). Leisure travel distribution patterns of Germans: Insights for climate policy. Case Studies on Transport Policy, 5(4), 596-603.

Goulden, M. (2011). Hyper-mobility or the end of the road? Retrieved 23 July 2013, from https://ceasefiremagazine.co.uk/hyper-mobility/

Hall, C. M., \& Ram, Y. (2017). Measuring the Relationship between Tourism and Walkability: Walk Score and English Tourist Attractions. Journal of Sustainable Tourism, In Press, 1-20.

Hanna, P., \& Adams, M. (2017). Positive self-representations, sustainability and socially organised denial in UK tourists: discursive barriers to a sustainable transport future. Journal of Sustainable Tourism, In press, 1-18.

Hardoon, D. (2017). An economy for the 99\%. It's time to build a human economy that benefits everyone, not just the privileged few (No. DOI: 10.21201/2017.8616). Oxford: Oxfam.

Hickman, R., \& Banister, D. (2005, June 2005). Towards a 60\% reduction in UK transport carbon dioxide emissions: A scenario building and backcasting approach. Paper presented at the ECEEE Conference, Nice.

Higham, J., Cohen, S., Peeters, P., \& Gössling, S. (2013). Psychological and behavioural approaches to understanding and governing sustainable mobility. Journal of Sustainable Tourism, 21(7), 949-967.

Hopkins, D., \& Higham, J. (Eds.). (2016). Low Carbon Mobility Transitions. Oxford, UK: Goodfellow Publishers.

Hubacek, K., Baiocchi, G., Feng, K., \& Patwardhan, A. (2017). Poverty eradication in a carbon constrained world. Nature Communications, 8(1), 912.

ICAO. (2016). Assembly Resolutions in Force (as of 6 October 2016) (No. Doc 10075). Montreal: ICAO.

ICAO. (2017a). Proposal for the First Edition of Annex 16, Volume IV, concerning Standards and Recommended Practices relating to the Carbon Offsetting and Reduction Scheme for International Aviation (CORSIA) (No. AN 1/17.14 - 17/129). Montreal: ICAO.

ICAO. (2017b). Proposed 1st Edition of ICAO Annex 16, Vol III. Annex 16 to the convention on international civil aviation volume iii aeroplane CO2 emissions. In EASA (Ed.), Notice of Proposed Amendment 2017-01. Implementation of the CAEP/10 amendments on climate change, emissions and noise (pp. 226-252). Cologne: European Aviation safety Agency.

IIASA. (2015). The GGI Scenario Database (Version 2.0). Retrieved 02-05-2015, 2015, from http://www.iiasa.ac.at/Research/GGI/DB/

IMAGE-team. (2006). The IMAGE 2.2 implementation of the SRES scenarios. A comprehensive analysis of emissions, climate change and impacts in the 21st century (No. CD-ROM 500110001 (former 481508018)). Bilthoven: National Institute for Public Health and the Environment.

IPCC. (2000). Special report on emission scenarios (No. ISBN-10: 0521800811 (web version)): International Panel on Climate Change.

IPCC. (2014a). Climate Change 2014: Impacts, Adaptation, and Vulnerability. Part A: Global and Sectoral Aspects. Contribution of Working Group II to the Fifth Assessment Report of the Intergovernmental Panel on Climate Change. Cambridge UK: Cambridge University Press.

IPCC. (2014b). Climate Change 2014: Mitigation of Climate Change. Contribution of Working Group III to the Fifth Assessment Report of the Intergovernmental Panel on Climate Change. Cambridge UK: Cambridge University Press.

IPCC. (2014c). Climate change 2014. Synthesis report. Contribution of Working Groups I, II and III to the Fifth Assessment Report of the Intergovernmental Panel on Climate Change. Geneva, Switzerland: IPCC.

Janta, H., Cohen, S. A., \& Williams, A. M. (2015). Rethinking Visiting Friends and Relatives Mobilities. Population, Space and Place, 21(7), 585-598.

Jantsch, E. (1967). Technological forecasting in perspective. A framework for technological forecasting, its techniques and organisation. Paris: OECD.

Kamp, C. (2017). Goal 11: Sustainable cities and communities. In E. Canada, K. Karschat, L. Jäger, C. Kamp, F. de Man, S. Mangalasseri, M. Maurer, A. Monshausen, C. Plüss, A. Rutherford \& C. Tremel (Eds.), Transforming Tourism: Tourism in the 2030 Agenda (pp. 63-68). Berlin, Germany.

Kantenbacher, J., Hanna, P., Miller, G., Scarles, C., \& Yang, J. (2017). Consumer priorities: what would people sacrifice in order to fly on holidays? Journal of Sustainable Tourism, In press, 1-16.

Lassen, C., Laugen, B. T., \& Næss, P. (2006). Virtual mobility and organizational reality - a note on the mobility needs in knowledge organisations. Transportation Research Part D: Transport and Environment, 11(6), 459-463.

Macmillan, A., \& Mackie, H. (2016). Optimising Low Carbon Mobility for Health and Equity. In Low Carbon Mobility Transitions (pp. 45-65). Oxford: Goodfellow Publishers Ltd. 
Mahashabde, A., Wolfe, P., Ashok, A., Dorbian, C., He, Q., Fan, A., Lukachko, S., Mozdzanowska, A., Wollersheim, C., Barrett, S. R. H., Locke, M., \& Waitz, I. A. (2011). Assessing the environmental impacts of aircraft noise and emissions. Progress in Aerospace Sciences, 47(1), 15-52.

Medlock, J. M., \& Leach, S. A. (2015). Effect of climate change on vector-borne disease risk in the UK. The Lancet Infectious Diseases, 15(6), 721-730.

Mowforth, M., \& Munt, I. (2015). Tourism and sustainability: Development, globalisation and new tourism in the third world. London: Routledge.

Mueller, V., Gray, C., \& Kosec, K. (2014). Heat stress increases long-term human migration in rural Pakistan. Nature Climate Change, 4, 182.

Mullen, C., \& Marsden, G. (2016). Mobility justice in low carbon energy transitions. Energy Research \& Social Science, 18, 109-117.

Murray, L., \& Young, C. (2017). Air departure tax: who benefits? Analysis for Scottish policymakers: Fellow Travellers.

Obersteiner, M., Bednar, J., Wagner, F., Gasser, T., Ciais, P., Forsell, N., Frank, S., Havlik, P., Valin, H., Janssens, I. A., Peñuelas, J., \& Schmidt-Traub, G. (2018). How to spend a dwindling greenhouse gas budget. Nature Climate Change, 8(1), 7-10.

Oguz, N. B., \& Ib, R. (1992). Normative Action Research. Organization Studies, 13(1), 019-034.

Page, S. J., Yeoman, I., Connell, J., \& Greenwood, C. (2010). Scenario planning as a tool to understand uncertainty in tourism: the example of transport and tourism in Scotland in 2025. Current Issues in Tourism, 13(2), 99 - 137.

Pang, S. F. H., McKercher, B., \& Prideaux, B. (2012). Climate Change and Tourism: An Overview. Asia Pacific Journal of Tourism Research, 18(1-2), 4-20.

Pappas, N. (2014). The Effect of Distance, Expenditure and Culture on the Expression of Social Status Through Tourism. Tourism Planning \& Development, 11(4), 387-404.

Peeters, P. M. (2013). Developing a long-term global tourism transport model using a behavioural approach: implications for sustainable tourism policy making. Journal of Sustainable Tourism, 21(7), 1049-1069.

Peeters, P. M. (2017). Tourism's impact on climate change and its mitigation challenges. How can tourism become 'climatically sustainable'? , Delft University of Technology, Delft.

Peeters, P. M., \& Dubois, G. (2010). Tourism travel under climate change mitigation constraints. Journal of Transport Geography, 18, 447-457.

Piketty, T. (2015). About capital in the twenty-first century. American Economic Review, 105(5), 48-53.

Prideaux, B., Laws, E., \& Faulkner, B. (2003). Events in Indonesia: exploring the limits to formal tourism trends forecasting methods in complex crisis situations. Tourism Management, 24(4), 475-487.

Quist, J., \& Vergragt, P. (2006). Past and future of backcasting: The shift to stakeholder participation and a proposal for a methodological framework. Futures, 38(9), 1027-1045.

Ram, Y., Nawijn, J., \& Peeters, P. M. (2013). Happiness and limits to sustainable tourism mobility: a new conceptual model. Journal of Sustainable Tourism, 21(7), 1017-1035.

Reynolds, T., Barrett, S., Dray, L., Evans, A., Köhler, M., Vera-Morales, M., Schäfer, A., Wadud, Z., Britter, R., \& Hallam, H. (2007). Modelling environmental and economic impacts of aviation: introducing the aviation integrated modelling project. Paper presented at the 7th AIAA ATIO Conf, 2nd CEIAT Int'l Conf on Innov and Integr in Aero Sciences, 17th LTA Systems Tech Conf; followed by 2nd TEOS Forum.

Rockstrom, J., Steffen, W., Noone, K., Persson, A., Chapin, F. S., Lambin, E. F., Lenton, T. M., Scheffer, M., Folke, C., Schellnhuber, H. J., Nykvist, B., de Wit, C. A., Hughes, T., van der Leeuw, S., Rodhe, H., Sorlin, S., Snyder, P. K., Costanza, R., Svedin, U., Falkenmark, M., Karlberg, L., Corell, R. W., Fabry, V. J., Hansen, J., Walker, B., Liverman, D., Richardson, K., Crutzen, P., \& Foley, J. A. (2009). Planetary Boundaries: Exploring the safe operating space for humanity. Ecology and Society, 14(2), 32.

Rogelj, J., Schaeffer, M., Friedlingstein, P., Gillett, N. P., van Vuuren, D. P., Riahi, K., Allen, M., \& Knutti, R. (2016). Differences between carbon budget estimates unravelled. Nature Clim. Change, 6(3), 245252.

Sanders, K., \& Sharockman, A. (2015). Bernie Sanders says 99 percent of 'new' income is going to top 1 percent. Retrieved 1 March 2018, 2018, from http://www.politifact.com/truth-ometer/statements/2015/apr/19/bernie-s/bernie-sanders-says-99-percent-new-income-goingto/

Schäfer, A., Heywood, J. B., Jacoby, h. D., \& Waitz, I. A. (2009). Transportation in a climate-constrained world. Cambridge, MA: MIT Press.

Schäfer, A., \& Victor, D. G. (2000). The future mobility of the world population. Transportation Research - A, 34, 171-205. 
Schewe, J., Heinke, J., Gerten, D., Haddeland, I., Arnell, N. W., Clark, D. B., Dankers, R., Eisner, S., Fekete, B. M., Colón-González, F. J., Gosling, S. N., Kim, H., Liu, X., Masaki, Y., Portmann, F. T., Satoh, Y., Stacke, T., Tang, Q., Wada, Y., Wisser, D., Albrecht, T., Frieler, K., Piontek, F., Warszawski, L., \& Kabat, P. (2014). Multimodel assessment of water scarcity under climate change. Proceedings of the National Academy of Sciences, 111(9), 3245-3250.

Schubert, R., Schellnhuber, H.-J., Buchmann, N., Epiney, A., Grießhammer, R., Kulessa, M., Messner, D., Rahmstorf, S., \& Schmid, J. (2008). Climate change as a security risk (No. ISBN 978-1-84407-5362). Berlin, Germany: German Advisory Council on Global Change (WBGU).

Schwartz, P. (1996). The art of the long view: Planning for the future in an uncertain world. Chichester (UK): John Wiley \& Sons, Ltd.

Scott, D., Gössling, S., \& Hall, C. M. (2012). International tourism and climate change. Wiley Interdisciplinary Reviews: Climate Change.

Scott, D., Hall, C. M., \& Gössling, S. (2016). A report on the Paris Climate Change Agreement and its implications for tourism: why we will always have Paris. Journal of Sustainable Tourism, 24(7), 933948.

Scuttari, A., Orsi, F., \& Bassani, R. (2018). Assessing the Tourism-Traffic Paradox in Mountain Destinations. A Stated Preference Survey on the Dolomites' Passes (Italy) Journal of Sustainable Tourism, In Press, $1-20$.

Sharpley, R., \& Telfer, D. J. (2014). Tourism and development: concepts and issues (Vol. 63). Bristol: Channel View Publications.

Smith, A., Robbins, D., \& Dickinson, J. (2017). Defining sustainable transport in rural tourism: experiences from the New Forest. Journal of Sustainable Tourism, In Press, 1-16.

Steve, H. L. Y., Gideon, L. L., In Hwan, L., Florian, A., Akshay, A., Fabio, C., Sebastian, D. E., Robert, M., \& Steven, R. H. B. (2015). Global, regional and local health impacts of civil aviation emissions. Environmental Research Letters, 10(3), 034001.

Strauss, L. (1949). Political Philosophy and History. Journal of the History of Ideas, 10(1), 30-50.

Tyner, J. A. (2013). Population geography I: Surplus populations. Progress in Human Geography, 37(5), 701711.

UNFCCC. (2015). Adoption of the Paris Agreement. Proposal by the President. Draft decision -/CP.21 (No. FCCC/CP/2015/L.9/Rev.1). Paris, France: Framework Convention on Climate Change.

United Nations. (2011). World Population Prospects: The 2010 Revision. Retrieved 15-01-2012, 2012, from http://esa.un.org/unpd/wpp/unpp/panel_indicators.htm

United Nations. (2018). Sustainable Development Knowledge Platform. Retrieved 1 February 2018, from https://sustainabledevelopment.un.org/

UNWTO. (2016). Compendium of tourism statistics. Data 2010-2014. 2016 Edition. Madrid: World Tourism Organisation.

UNWTO, \& WTM. (2017). Minister's Summit 2017 from http://www2.unwto.org/unwto-wtm-ministerssummit-2017

Urry, J. (2003). Social networks, travel and talk1. The British Journal of Sociology, 54(2), 155-175.

van der Ploeg, F. (2018). The safe carbon budget. Climatic Change, 147(1), 47-59.

van Notten, P. W. F., Rotmans, J., van Asselt, M. B. A., \& Rothman, D. S. (2003). An updated scenario typology. Futures, 35, 423-443.

Van Wee, B., \& Geurs, K. (2004). Backcasting as a tool for sustainable transport policy making: the Environmental Sustainable Transport study in the Netherlands. European Journal of Transport and Infrastructure Research 4 (1) pp. 47-69.

Watts, N., Adger, W. N., Agnolucci, P., Blackstock, J., Byass, P., Cai, W., Chaytor, S., Colbourn, T., Collins, M., \& Cooper, A. (2015). Health and climate change: policy responses to protect public health. The Lancet, 386(10006), 1861-1914.

White, R. (2016). Criminality and climate change. Nature Clim. Change, 6(8), 737-739.

Young, M., Markham, F., Reis, A. C., \& Higham, J. E. S. (2015). Flights of fantasy: A reformulation of the flyers' dilemma. Annals of Tourism Research, 54(0), 1-15. 